\title{
Pendidikan Karakter dalam Buku Sirah Nabawiyah Karya Syaikh Shafiyyurrahman al-Mubarakfuri
}

\author{
${ }^{1 *}$ Riska Izani, ${ }^{2}$ Rubini \\ 12STAI Masjid Syuhada Yogyakarta \\ 1*izaniriska98@gmail.com,2Rubinihr80@gmail.com
}

\begin{abstract}
Abstrak: Pendidikan karakter merupakan salah satu unsur penting dari pendidikan. Pendidikan karakter tidak hanya menjadi tanggung jawab orang tua atau pendidik di sekolah saja. Namun setiap pihak dapat berpengaruh dalam menanamkan pendidikan karakter terhadap peserta didik. Membentuk peserta didik menjadi seseorang yang religius dapat diupayakan dengan cara menyampaikan nilai-nilai Islam melalui Sejarah Islam, terutama perjuangan Rasulullah Saw dan para sahabat. Tujuan dari kajian ini adalah mengetahui pendidikan karakter dalam buku Sirah Nabawiyah karya Syaikh Shafiyyurrahman al-Mubarakfuri. Jenis penelitian ini adalah kajian pustaka atau library research, dengan pendekatan deskriptif, metode pengumpulan data adalah metode dokumentasi. Data primer dalam penlitian ini adalah buku Sirah Nabawiyah karya Syaikh Shafiyyurrahman al-Mubarakfuri. Teknik analisis data adalah content analys melalui 3 langkah yaitu editing, organizing dan inferensi. Hasil penelitian adalah pendidikan karakter dalam buku Sirah Nabawiyahkarya syaikh Shafiyyurrahman al-Mubarakfuri adalah Ketulusan hati atau kejujuran (honesty), Belas kasihan (compassion), Kegagah beranian (courage), Kasih sayang (kindness), Kontrol diri (self-control), Kerja sama (cooperation), Kerja keras (hard work).
\end{abstract}

Kata kunci: Pendidikan Karakter, Buku Sirah Nabawiyah, Kerja Keras, Kerjasama,

Abstract: Character education is a crucial element of education. Character education is not only the responsibility of parents or educators at school. However, each party can influence instilling character education for students. Shaping students into religious people can pursue by conveying Islamic values through Islamic history, especially the struggles of the Prophet Muhammad and his companions. The purpose of this study is to determine character education in the book Sirah Nabawiyah by Shafiyyurrahman al-Mubarakfuri. This type of research is library research or library research. With a descriptive approach, the data collection method is the documentation method. The primary data in this research is the book Sirah Nabawiyah by Shafiyyurrahman al-Mubarakfuri. The data analysis technique is content analysis through 3 steps, namely editing, organizing and inference. The results of the research are character education in the book Sirah Nabawiyah by Shafiyyurrahman alMubarakfuri is sincerity or honesty compassion, courage, kindness, self-control, cooperation, hard work (hard work).

Keywords: Character Education, Sirah Nabawiyah Book, Hard Work, Cooperation,

\section{PENDAHULUAN}

Pendidikan karakter merupakan hal penting dalam dunia pendidikan. Keadaan peserta didik yang memiliki karakter kurang baik menjadi salah satu latar belakang 
digalakannya pendidikan karakter. ${ }^{1}$ Pada masa kini sering kita jumpai peserta didik dengan karakter yang tidak baik, seperti tidak hormat kepada orang tua, tidak jujur, kurang memiliki rasa tanggung jawab, melakukan penyimpangan syari'at atau ketentuan-ketentuan agama serta tidak sesuai dengan nilai-nilai sosial di masyarakat. Dengan adanya fenomena tersebut, maka pendidikan karakter sangat diperlukan untuk mencegah sekaligus menanggulangi hal tersebut.

Pendidikan karakter membutuhkan adanya contoh yang tepat agar peserta didik dapat mengambil pelajaran melalui sebuah teladan nyata. Salah satu cara yang bisa ditempuh tentunya dengan menyampaikan hal yang memiliki unsur pendidikan karakter. ${ }^{2}$ Dalam kajian ini, pendidikan karakter akan disampaikan melalui Sirah Nabawiyah atau sejarah Rasulullah dan para sahabatnya.

Pendidikan karakter merupakan hal penting dalam dunia pendidikan. Keadaan peserta didik yang memiliki karakter kurang baik menjadi salah satu latar belakang digalakannya pendidikan karakter. Pada masa kini sering kita jumpai peserta didik dengan karakter yang tidak baik, seperti tidak hormat kepada orang tua, tidak jujur, kurang memiliki rasa tanggung jawab, melakukan penyimpangan syari'at atau ketentuan-ketentuan agama serta tidak sesuai dengan nilai-nilai sosial di masyarakat. Dengan adanya fenomena tersebut, maka pendidikan karakter sangat diperlukan untuk mencegah sekaligus menanggulangi hal tersebut. ${ }^{3}$

Pendidikan karakter membutuhkan adanya contoh yang tepat agar peserta didik dapat mengambil pelajaran melalui sebuah teladan nyata. Salah satu cara yang bisa ditempuh tentunya dengan menyampaikan hal yang memiliki unsur pendidikan karakter. Dalam makalah ini, pendidikan karakter akan disampaikan melalui sirah nabawiyah atau sejarah Rasulullah dan para sahabatnya. Pembahasan terkait pendidikan akhlak ini dibahas dalam beberapa ayat Al-Qur'an antara lain:

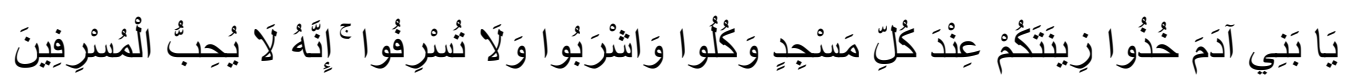
Artinya: Hai anak Adam, pakailah pakaianmu yang indah di setiap (memasuki) mesjid, makan dan minumlah, dan janganlah berlebih-lebihan. Sesungguhnya Allah tidak menyukai orang-orang yang berlebih-lebihan (QS. al-A'raf: 31)

${ }^{1}$ Hadi Wiyono, 'PENDIDIKAN KARAKTER DALAM BINGKAI PEMBELAJARAN DI SEKOLAH', no. 2 (2012): 18.

2 Universitas Brawijaya and Abdul Halim Rofi'ie, 'PENDIDIKAN KARAKTER ADALAH SEBUAH KEHARUSAN', WASKITA: Jurnal Pendidikan Nilai dan Pembangunan Karakter 1, no. 1 (1 May 2017): 113-28, https://doi.org/10.21776/ub.waskita.2017.001.01.7. untuk pembacaan lebih lanjut lihat Moh Toriqul Chaer, Alef Theria Wasim, and Akif Khilmiyah, 'Character Education for Single Parent Children in the Quran' (1st Annual Internatioal Conference on Social Sciences and Humanities (AICOSH 2019), Atlantis Press, 2019), 36-39, https://doi.org/10.2991/aicosh-19.2019.7.

${ }^{3}$ Nopan Omeri, 'PENTINGNYA PENDIDIKAN KARAKTER DALAM DUNIA PENDIDIKAN', n.d., 5. 


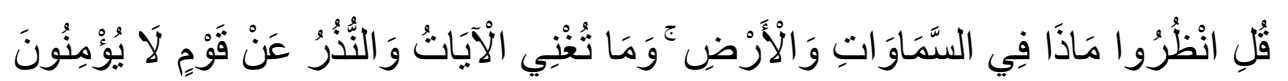

Artinya: Katakanlah: "Perhatikanlah apa yang ada di langit dan di bumi. Tidaklah bermanfaat tanda kekuasaan Allah dan rasul-rasul yang memberi peringatan bagi orang-orang yang tidak beriman (QS. Yunus: 101).

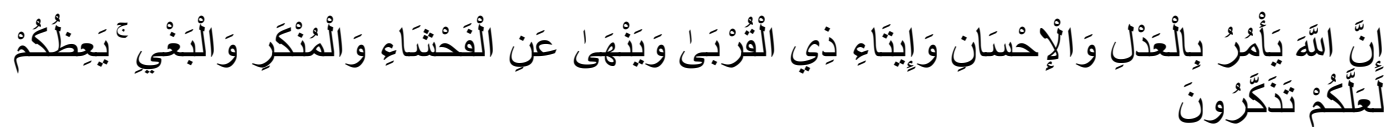

Artinya: Sesungguhnya Allah menyuruh (kamu) berlaku adil dan berbuat kebajikan, memberi kepada kaum kerabat, dan Allah melarang dari perbuatan keji, kemungkaran dan permusuhan. Dia memberi pengajaran kepadamu agar kamu dapat mengambil pelajaran (QS. an-Nahl: 90).

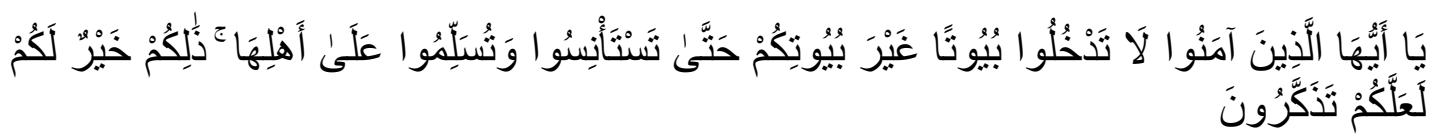

Artinya: Hai orang-orang yang beriman, janganlah kamu memasuki rumah yang bukan rumahmu sebelum meminta izin dan memberi salam kepada penghuninya. Yang demikian itu lebih baik bagimu, agar kamu (selalu) ingat (QS. an-Nur: 27).

Berdasar ayat-ayat Al-Qur'an diatas kita ketahui bahwa pendidikan yang disampaikan dalam Al-Qur'an lebih mengutamakan pada pendidikan karakter. Adapun menurut Yusuf Qaradhawi: "pendidikan karakter Islam merupakan pendidikan manusia seutuhnya baik akal maupun hati, rohani dan jasmani, akhlak dan keterampilan. Sebab pendidikan Islam menyiapkan manusia untuk hidup, baik dalam perang dan menyiapkan untuk menghadapi masyarakat dengan segala kebaikan dan kesejahteraannya, manis dan pahitnya. ${ }^{4}$

Menurut Thomas Lickona ada 7 unsur utama dalam pendidikan karakter antara lain; 1) Ketulusan hati atau kejujuran (honesty); 2) Belas kasihan (compassion); 3) Kegagah beranian (courage); 4) Kasih sayang (kindness); 5) Kontrol diri (self-control); 6) Kerja sama (cooperation); 7) Kerja keras (hard work). ${ }^{5}$

4 Yusuf Qaradhawi, Pendidikan Islam dan Madrasah Hasan al-Banna, terj. Bustami A. Ghani dan Zainal Abidin Ahmad, (Jakarta: Bulan Bintang. 1980), 39 baca juga Siti Farida, 'PENDIDIKAN KARAKTER DALAM PRESPEKTIF ISLAM' 1, no. 1 (2016): 10; Johansyah Johansyah, 'PENDIDIKAN KARAKTER DALAM ISLAM; Kajian dari Aspek Metodologis', Jurnal Ilmiah Islam Futura 11, no. 1 (3 February 2017): 85, https://doi.org/10.22373/jiif.v11i1.63.

5 Muhammad Ahsani, 'STUDI KOMPARASI PEMIKIRAN THOMAS LICKONA DAN ABDULLAH NASHIH ULWAN TENTANG PENDIDIKAN KARAKTER KELUARGA DAN SEKOLAH', Didaktika Religia 2,no. 2 (24 July 2014), https://doi.org/10.30762/didaktika.v2i2.141., sebagai perbandingan lihat Wiyono, 'PENDIDIKAN KARAKTER DALAM BINGKAI PEMBELAJARAN DI SEKOLAH'. Dan Ahsani, 'STUDI KOMPARASI PEMIKIRAN THOMAS LICKONA DAN ABDULLAH NASHIH ULWAN TENTANG PENDIDIKAN KARAKTER KELUARGA DAN SEKOLAH'. 
Metode penelitian dalam makalah ini terdiri dari jenis penelitian adalah library research atau kajian pustaka yaitu penelitin dengan teknik pengumpulan data dengan mengadakan studi penelaahan terhadap buku-buku, literatur-literatur, catatancatatan, dan laporan-laporan yang ada hubungannya dengan masalah yang dipecahkan".6 dengan pendekatan deskriptif, data primer pada penelitian ini adalah buku Sirah Nabawiyah karya syaikh shafiyyurrahman al-mubarakfuri. Metode pengumpulan data adalah metode dokumentasiTeknik analisis data adalah content analys melalui 3 langkah yaitu editing, organizing dan inferensi.

\section{PEMBAHASAN}

Dalam Pendidikan karakter yang akan dibahas dalam makalah ini merupakan pendidikan karakter melalui kisah-kisah perjuangan Rasulullah dan para sahabat yang terdapat dalam buku siroh nabawiyah karya syaikh Shafiyyurrahman alMubarakfuri adalah:

1. Ketulusan hati atau kejujuran (honesty)

Keluarga Yasir adalah teladan umat. Yasir, Sumayah (istri Yasir) dan Ammar (anak Yasir) memiliki andil cukup besar bagi perjalanan dakwah Islam. Mereka telah mendapat siksaan, yang menurut ukuran manusia amatlah mustahil untuk tetap istiqamah, yaitu ketika majikannya (keluarga Bani Makhzum) mengetahui bahwa keluarga Yasir masuk Islam, kemudian menimpakan berbagai siksaan amat pedih kepada keluarga tersebut.

Dipaksanya keluarga itu untuk keluar dari Islam, dan kembali kepada agama berhala yang penuh kekufuran. Suatu hari, di saat matahari padang pasir tengah membara, di sebuah lapangan terbuka di kawasan kota Mekkah, satu keluarga itu tengah menerima siksaan tidak terperikan. Berhari-hari lamanya siksaan itu telah mereka derita.

Tatkala Rasulullah Saw berlalu dari hadapan keluarga itu, tiba-tiba terdengarlah rintihan Yasir dalam keadaan terbelenggu kedua tangan dan kakinya, "Adakah derita ini sepanjang masa?" Segera Rasulullah menengadah ke langit seraya berseru, "Wahai keluarga Yasir, bersabarlah. Bergembiralah kamu. Sesungguhnya surga telah dipersiapkan sebagai tempat kembali keluargamu." Mendengar seruan Rasulullah tersebut, keluarga Yasir menjadi tenteram jiwanya dan menjadi tabah dalam menghadapi ujian.

Walaupun keluarga mereka mendapat ancaman dari berbagai pihak mereka tetap teguh dalam keislamannya. Abu Jahal menjadi salah satu orang yang sangat gencar menekan keluarga Yasir. Dia mengancam keluarga itu untuk memilih

${ }^{6}$ Nazir, Metode Penelitian, (Indonesia: Ghalia, 1988), 111 
antara mati akibat keislamannya atau kembali hidup tentram dengan syarat meninggalkan agama Islam dan kembali menyembah berhala.

Keluarga Yasir tetap berpihak dan teguh dalam Islam. Meski siksaan demi siksaan selalu mereka dapati hingga akhirnya Sumayyah meninggal dunia. Meninggalnya Sumayyah merupakan saksi atas keteguhan hatinya memegang erat kebenaran yang diyakininya. Sumayyah menjadi wanita pertama yang menyandang gelar syahidah dalam sejarah perjuangan Islam. Disusul suaminya, Yasir sebagai lelaki pertama yang bergelar sebagai syuhada.

Setelah kematian ayah dan ibunya, Ammar tetap bergulat menanggung siksaan. Dia tetap berupaya menanggung siksaan walaupun dirasa sangat pedih. Namun Ammar bin Yasir tetaplah manusia biasa. Sesungguhnya siksaan yang dia terima telah melampaui batas kemanusiaan, hingga tanpa sadar Ammar pun mengucapkan kata-kata kekufuran sebagai upaya melepaskan siksaan yang dia derita.

Sungguh Ammar bersedih dengan ucapan itu, walaupun dalam hatinya tetap menyakiti sepenuhnya akan kebenaran Islam. Pada saat itu turunlah kebenaran Allah Subhanahu Wa Ta'ala, "Barangsiapa yang kafir kepada Allah sesudah ia beriman (dia mendapat kemurkaan Allah), kecuali orang yang dipaksa kafir padahal hatinya tetap tenang dalam keadaan beriman (dia tidak berdosa)." (QS. An-Nahl: 106).

Dari sejarah hidup keluarga Yasir kita belajar untuk senantiasa melakukan segala sesuatu dengan hati yang tulus. Yasir, Sumayah dan Ammar beriman kepada Allah dan Rasul-Nya dengan tulus. Ketulusan tersebut mengalahkan sakit dan perihnya siksa para kaum kafir Quraisy. Berkat ketulusan hati keluarga Yasir mereka mendapatkan keridhan dari Allah dalam bentuk yang berbeda yaitu suami istri Yasir dan Sumayyah mendapatkan syahid pasca mendapat siksaan demi siksaan, sedangkan anaknya Ammar bin Yasir yang sempat megucapkan kalimat kekufuran namun kemudian menyampaikan keadaan yang sesungguhnya dihadapan Rasulullah SAW dengan jujur disertai dengan bertaubat maka dia menjadi salah satu sahabat Rasulullah yang agung.

2. Belas kasihan (compassion)

Bilal adalah salah satu budak dari bangSawan Quraisy yang bernama Umayyah bin Khalaf. Mereka sering menyiksa Bilal dengan mencambuk punggung Bilal, namun Bilal hanya berkata, "Ahad, Ahad, Ahad.." Penyiksaan yang dilakukan Umayyah dan para algojonya sangatlah tidak manusiawi. Mereka menindih dada telanjang Bilal dengan batu besar yang panas di tengah terik padang pasir. 
Penyiksaan yang dilakukan oleh Umayyah tidak berhenti sampai disitu. Kadang Umayyah bin Khalaf menyiksa Bilal dengan mengikat lehernya menggunakan tali yang kasar lalu menyerahkannya kepada sejumlah orang yang tidak memiliki belas kasihan untuk menariknya di sepanjang jalan Mekah. Selama penyiksaan tersebut Bilal hanya mengucapkan "Ahad, Ahad, Ahad.."Sementara itu, Bilal menikmati siksaan yang diterimanya karena membela ajaran Allah dan Rasul-Nya.

Suatu ketika, Abu Bakar Rodhiallahu 'anhu mengajukan penawaran kepada Umayyah bin Khalaf untuk membeli Bilal. Umayyah menaikkan harga berlipat ganda, dengan harapan Abu Bakar akan mengurungkan niatnya untuk membeli Bilal. Namun ternyata, Abu Bakar setuju, walaupun harus mengeluarkan 9 uqiyat emas (1 uqiyat emas $=285,73$ gr x Rp 400.000) setara dengan uang sekitar Rp 114.291.000.

Seusai transaksi, Umayyah berkata kepada Abu Bakar, "Sebenarnya, kalau engkau menawar sampai satu uqiyah-pun, maka aku tidak akan ragu untuk menjualnya." Abu Bakar membalas, "Seandainya engkau memberi tawaran sampai seratus uqiyah-pun, maka aku tidak akan ragu untuk membelinya." Ketika Abu Bakar memberi tahu Rasulullah Saw bahwa ia telah memerdekaan Bilal dengan membelinya sekaligus menyelamatkan Bilal dari siksa tuannya Umayyah, Rasulullah Saw berkata kepada Abu Bakar, "Kalau begitu, biarkan aku bersekutu denganmu untuk membayarnya, wahai Abu Bakar." Abu Bakar Ash-Shiddiq Rodhiallahu 'anhu menjawab, "Aku telah memerdekakannya, wahai Rasulullah."

Abu Bakar Ash-Shiddiq merupakan salah satu sahabat yang miliki rasa belas kasih yang sangat tinggi. Salah satu hal yang membuat Abu Bakar menjadi mulia adalah dengan karakter tersebut. Walaupun harus mengeluarkan biaya yang tidak sedikit Abu Bakar Ash-Shiddiq tetap ikhlas dalam melakukannya. Hal ini dapat djadikan sebagai teladan dalam pendidikan karakter.

3. Kegagah beranian (courage)

Abdullah bin Mas'ud r.a berkata, " sebelum Umar memeluk Islam, kami tidak bisa melaksanakan shalat di dekat Ka'bah. Ali r.a berkata," Pada mulanya semua orang Islam akan hijrah, mereka melakukannya dengan sembunyisembunyi, namun ketika Umar r.a berniat untuk hijrah dia menggantungkan pedang dilehernya sambil memegang busur panah ditangannya dilengkapi dengan anak panah yang banyak. Pertama-tama dia mendatangi masjid dan melakukan tawaf dengan tenangnya dan mengerjakan shalat dengan khusyu'. Setelah itu dia mendatangi kumpulan orang-orang kafir, lalu berkata, 
"Barangsiapa ingin ibunya menangisi kematian anaknya, isterinya menjadi janda, anak-anaknya menjadi yatim, maka keluarlah dan hadapi aku untuk bertempur. Dia pun mendatangi perkumpulan yang lainnya sambil berkata seperti tadi. Tetapi tidak ada satu orang kafir pun yang berani menghadapi tantangannya. Pendidikan karakter dari kisah Umar bin Khattab di atas yaitu tentang kegagah beranian. Hal ini ditunjukan dengan sikap Umar bin Khattab yang dengan terangterangan menantang orang-orang kafir yang biasanya menyiksa kaum muslim.

4. Kasih sayang (kindness)

Salah satu sudut di dekat pintu kota Madinah menjadi tempat seorang pengemis buta. Dia memiliki kepercayaan Yahudi. Setiap kali ada orang yang mendekatinya, dia selalu berpesan, "Jangan pernah engkau dekati Muhammad. Dia itu orang gila, pembohong, dan tukang sihir." Seandainya dia tidak buta, tentunya cepat berubah sikap dan perangai. Sebab, adalah Rasulullah Saw yang gemar mendatanginya. Bukan untuk menghardiknya atau sekadar meminta klarifikasi atas hasutannya itu. Rasulullah Saw justru rajin datang kepadanya dengan membawakan makanan.

Tanpa bicara sepatah kata pun, Rasulullah Saw lantas duduk di sebelah pengemis Yahudi buta itu. Setelah meminta izin, Rasulullah Saw pun menyuapi orang tadi dengan penuh kasih sayang. Hal itu dilakukannya rutin, bahkan kemudian menjadi kebiasaan. Seiring waktu, Allah SWT memanggil beliau. Rasulullah Saw wafat, menyisakan duka yang teramat dalam di tengah para keluarga, sahabat, dan kaum Muslimin pada umumnya. Sementara itu, kepemimpinan umat sudah berada di tangan Abu Bakar ash-Shiddiq. Sang khalifah ini memang sudah bertekad untuk mengikuti tradisi dan kebijakan-kebijakan peninggalan Rasulullah Saw. Bahkan termasuk rutinitasnya sehari-hari.

Suatu hari, Abu Bakar berkunjung ke rumah putrinya, Aisyah. Abu Bakar bertanya kepada anaknya yang juga istri Rasulullah itu. "Wahai putriku, adakah satu sunnah kekasihku (Rasulullah Saw) yang belum aku tunaikan?" tanya Abu Bakar. Aisyah pun menjawab, "Wahai ayahku, engkau adalah seorang ahli sunnah, dan hampir tidak ada satu sunnah pun yang belum engkau lakukan kecuali satu saja". "Apakah itu?" "Setiap pagi Rasulullah Saw selalu pergi ke ujung pasar dengan membawakan makanan untuk seorang pengemis Yahudi buta yang sering duduk di sana," ungkap Aisyah.

Maka keesokan harinya, Abu Bakar pergi ke pasar dengan membawa makanan. Dia pun bergegas menuju titik lokasi yang dimaksud, supaya berjumpa dengan si pengemis. Betapa gembira Abu Bakar mendapati adanya seorang 
pengemis buta yang duduk di dekat sana. Setelah mengucapkan salam, Abu Bakar lalu duduk dan meminta izin kepadanya untuk menyuapinya.

Namun, di luar dugaan pengemis tadi malah murka dan membentak-bentak, "Siapakah kamu!?" Abu Bakar menjawab, "Aku ini orang yang biasa menyuapimu." "Bukan! engkau bukan orang yang biasa mendatangiku," teriak si pengemis lagi, "Jikalau benar kamu adalah dia, maka tidak susah aku mengunyah makanan di mulutku. Orang yang biasa mendatangiku itu selalu menghaluskan makanan terlebih dahulu dengan mulutnya sendiri. Barulah kemudian dia menyuapiku dengan itu," terang si pengemis sambil tetap meraut wajah kesal. Abu Bakar tidak kuasa menahan deraian air matanya, "Aku memang bukan orang yang biasa datang kepadamu. Aku adalah salah seorang dari sahabatnya, Abu Bakar. Orang mulia itu telah tiada. Dia adalah Rasulullah Muhammad Saw."

Mendengar penjelasan Abu Bakar, pengemis tadi seketika terkejut. Dia lalu menangis keras. Setelah tenang, dia bertanya memastikan, "Benarkah demikian? Selama ini aku selalu menghina, memfitnah, dan menjelek-jelekan Rasulullah. Padahal, belum pernah aku mendengar dia memarahiku sedikit pun. Dia yang selalu datang kepadaku setiap pagi dengan membawakan makanan. Dia begitu mulia." Maka di hadapan Abu Bakar ash-Shiddiq, pengemis Yahudi buta itu mengucapkan dua kalimah syahadat. Demikianlah, dia masuk Islam karena menyadari betapa mulianya akhlak Rasulullah Saw.

Kisah Rasulullah yang memberikan kasih sayangnya kepada seorang pengemis yahudi yang buta ini dapat menjadi teladan dalam pendidikan karakter. Hal ini dapat menginsiprasi peserta didik supaya dapat berkasih sayang terhadap sesama makhluk Allah. Sebab dengan berkasih sayang akan mendatangkan hikmah yang baik pula.

\section{Kontrol diri (self-control)}

Di masa perang Khandaq, umat Islam pernah ditantang duel Amr bin Abd Wad al-Amiri, salah satu pembesar musyrikin Quraisy yang sangat ditakuti. Rasulullah bertanya kepada para sahabat tentang siapa yang akan memenuhi tantangan ini. Para sahabat terlihat gentar. Nyali mereka menciut.

Dalam situasi ini Ali bin Abi Thalib maju, menyanggupi ajakan duel Amr bin Abd Wad. Melihat Ali yang masih terlalu muda, Rasulullah lantas mengulangi tawarannya kepada para sahabat. Hingga tiga kali, memang hanya Ali yang menyatakan berani melawan jawara Quraisy itu. Amr bin Abd Wad menanggapinya dengan tertawa mengejek. Namun faktanya, selama perkelahian nasib mujur tetap ada di tangan Ali. 
Usai paha kekarnya disabet pedang, Amr bin Abd Wad pun tumbang ke tanah. Kemenagan Ali sudah di depan mata. Hanya dengan sedikit gerakan saja, nyawa musuh dipastikan melayang. Dalam situasi terpojok Amr bin Abd Wad masih menyempatkan diri membrontak. Tiba-tiba ia meludahi wajah sepupu Rasulullah itu. Menaggapi hinaan ini, Ali justru kian pasif. Ali menyingkir dan mengurungkan niat membunuh hingga beberapa saat. "Saat dia meludahi wajahku, aku marah. Aku tidak ingin membunuhnya lantaran amarahku. Aku tunggu sampai lenyap kemarahanku dan membunuhnya semata karena Allah SWT," kata Ali menjawab kegelisahan sebagian sahabat atas sikapnya.

Meskipun Amr bin Abd Wad akhirnya gugur di tangan Ali, proses peperangan ini memberikan beberapa pelajaran. Perjuangan dan pembelaan Islam harus didasarkan pada ketulusan iman, bukan kebencian dan kemarahan. Sahabat Rasulullah yang kelak menjadi khalifah keempat ini juga menjernihkan bahwa spirit ketuhanan adalah satu-satunya landasan, mengalahan nafsu keinginan di balik ego pribadi dan golongan. Hal ini merupakan teladan nyata betapa Ali bin Abi Thalib pandai dalam mengontrol dirinya.

6. Kerja sama (cooperation)

Kerja sama menjadi poin penting salah satu karakter yang harus dimiliki peserta didik. Maka dari itu kita dapat mendapatkan pendidikan karakter berupa kerja sama melalui kisah Rasulullah dalam membangun parit di Madinah. Meski telah berubah, tempat tersebut dahulu menjadi saksi umat Islam Madinah bertahan dalam pertempuran besar, yaitu Perang Ahzab. Serangan itu bermula dari kedatangan 20 orang Yahudi ke Makkah.

Kedatangan pimpinan Yahudi dan pemuka Bani an-Nadhir itu bertujuan untuk memprovokasi Quraisy agar menyerang Rasulullah. Pemimpin Yahudi juga memprovokasi suku Ghathafan. Pasukan gabungan sebanyak sepuluh ribu orang itu akan menyerang Rasulullah di Madinah. Akan tetapi, berita serangan itu sampai di telinga Rasulullah, sehingga Rasullullah bermusyawarah dengan para sahabat. Dalam rapat itu, Salman al-Farisi menjadi bintang. Dia mengusulkan kepada Nabi Muhammad untuk membangun parit di sebelah utara Kota Madinah untuk menghalau musuh. Strategi yang baru dikenal itu segera disetujui Rasulullah. Utara Kota Madinah merupakan satu-satunya pintu masuk pasukan Quraisy. Rasulullah segera mengajak seribuan orang untuk membuat parit.

Dalam Hadis Bukhari disebutkan, Rasulullah pun ikut turun menggali parit itu. Bekerja sama bersama para sahabat yang lain. Para sahabat pernah mengadukan sulitnya memecah batu saat penggalian parit besar tersebut. 
Rasulullah yang mendengar kesulitan itu segera berdoa. "Bismillah," ujar Rasulullah.

Rasulullah menghantamkan palunya. Usai memukulkan palunya, dia kembali bertakbir seraya berdoa menaklukkan Syam. Pada pukulan kedua Rasulullah kembali berdoa. Dia pun mengiringinya dengan harapan menaklukkan Persia. Sedangkan pada pukulan ketiga, Rasulullah berharap dapat diberi kunci kerajaan Yaman. Parit tersebut tercatat dapat terselesaikan hanya selama lima sampai enam hari saja.Hal ini dapat terjadi karena adanya kerja sama yang baik antara Rasulullah dan para sahabat.

Pembangunan parit tersebut tidak akan berhasil jika tidak dilakukan dengan cara kerja sama. Manusia sebagai makhluk sosial pastinya membutuhkan orang lain dalam melakukan aktifitasnya dalam kehidupan sosial. Termasuk pula dalam pembangunan parit zaman Rasulullah sebagi salah satu stratei perang, diperlukan kerja sama yang baik.

7. Kerja keras (deligence or hard work)

Rasulullah menjadi teladan dalam berbagai hal salah satunya kerja keras. Perjuangan Rasulullah dalam berdakwah mengalami banyak halangan dan rintangan, namun berkat kerja kerasnya Rasulullah mampu membangun sebuah peradaban di Madinah.

Keberhasilan Rasulullah dalam membangun peradaban tidak luput dari kerja kerasnya mendakwahkan Islam hingga dihina dan tersiksa. Seperti yang Rasulullah alami ketika berdakwah kepada kaum Thaif. Rasulullah dihinakan dan disiksa, hingga tubuhnya yang mulia jatuh terjerembab dan terluka. Namun Rasulullah tidak pernah patah semangat. Rasulullah tetap bekerja keras untuk mendakwahkan Islam.

Cara selanjutnya yang ditempuh Rasulullah yaitu dengan berhijrah. Sebelum peristiwa hijrah ke Madinah, Rasulullah mengutus beberapa sabahat untuk berhijrah ke Habasyah. Dalam rangka mendakwahkan Islam kepada Raja Najasyi dan masyarakat Habasyah. Peristiwa hijrahnya para sahabat ke Habasyah tidak disertai dengan Rasulullah. Karena Rasulullah sedang berjuang membela kaum muslim yang masih berada di Mekah. Hingga akhirnya datanglah orang-orang Madinah yang meminta Rasulullah untuk menjadi pemimpin mereka.

Rasulullah menghabiskan waktunya selama 10 tahun di Madinah untuk melakukan dakwah. Sehingga masyarakat jazirah Arab memutuskan untuk memeluk agama Islam. Rasulullah pun memerintahkan para sahabatnya untuk melakukan dakwah ke berbagai daerah maupun penjuru dunia lainnya. Kerja 
keras Rasulullah membuahkan hasil yang baik hingga Islam dapat tersebar sampai ke sebagian besar jazirah arab bahkan penjuru dunia. Hal ini dapat dijadikan teladan dalam menanamkan pendidikan karakter berupa kerja keras.

\section{KESIMPULAN}

Peneliti Pendidikan karakter yang terdapat melalui Sirah Nabawiyah. Melalui kisah Rasulullah dan para sahabat, kita dapat berupaya menanamkan pendidikan karakter. Hal ini dapat menjadi cara yang efektif karena peserta didik akan mendapatkan teladan yang nyata dari kisah Rasulullah dan para sahabat tersebut. Maka tidak akan ada kata mustahil peserta didik memiliki karakter yang baik seperti yang dikemukakan dalam teori, karena hal tersebut telah dimiliki oleh orang-orang muslim sebelum kita. Pendidikan karakter dalam buku sirah nabawiyah karya karya syaikh shafiyyurrahman al-mubarakfuri adalah Ketulusan hati atau kejujuran (honesty), Belas kasihan (compassion), Kegagah beranian (courage), Kasih sayang (kindness), Kontrol diri (self-control), Kerja sama (cooperation), Kerja keras (hard work).

\section{DAFTAR PUSTAKA}

Ahsani, Muhammad. 'STUDI KOMPARASI PEMIKIRAN THOMAS LICKONA DAN ABDULLAH NASHIH ULWAN TENTANG PENDIDIKAN KARAKTER KELUARGA DAN SEKOLAH'. Didaktika Religia 2, no. 2 (24 July 2014). https://doi.org/10.30762/didaktika.v2i2.141.

Al-Mubarakfuri, Shafiyyurrahman. 2008. Sirah Nabawiyah. Jakarta: Pustaka AlKautsar.

As-Suyuthi, Imam. 2000. Tarikh Khulafa'. Jakarta: Pustaka Al-Kutsar.

Chaer, Moh Toriqul, Alef Theria Wasim, and Akif Khilmiyah. 'Character Education for Single Parent Children in the Quran', 36-39. Atlantis Press, 2019. https://doi.org/10.2991/aicosh-19.2019.7.

Farida, Siti. 'PENDIDIKAN KARAKTER DALAM PRESPEKTIF ISLAM’ 1, no. 1 (2016): 10.

Johansyah, Johansyah. 'PENDIDIKAN KARAKTER DALAM ISLAM; Kajian dari Aspek Metodologis'. Jurnal Ilmiah Islam Futura 11, no. 1 (3 February 2017): 85. https://doi.org/10.22373/jiif.v11i1.63.

Lickona, Thomas. 2012. Mendidik Untuk Membentuk Karakter. Jakarta: PT Bumi Aksara.

Nazir, Metode Penelitian, 1988, Indonesia: Ghalia

Omeri, Nopan. 'PENTINGNYA PENDIDIKAN KARAKTER DALAM DUNIA PENDIDIKAN', n.d., 5. 
Qaradhawi, Yusuf. 1980. Pendidikan Islam dan Madrasah Hasan al-Banna. Jakarta: Bulan Bintang.

Universitas Brawijaya, and Abdul Halim Rofi'ie. 'PENDIDIKAN KARAKTER ADALAH SEBUAH KEHARUSAN'. WASKITA: Jurnal Pendidikan Nilai dan Pembangunan $\begin{array}{lllllll}\text { Karakter } & 1 & \text { no. } & 1 & (1 & \text { May } & \text { 2017): }\end{array}$ https://doi.org/10.21776/ub.waskita.2017.001.01.7.

Wiyono, Hadi. 'PENDIDIKAN KARAKTER DALAM BINGKAI PEMBELAJARAN DI SEKOLAH', no. 2 (2012): 18. 